\title{
Management of Grass Pollen Allergy with 5-Grass Pollen Tablet: Results of a 2-Year Real-Life Study
}

\author{
Kija Shah-Hosseini · Eva-Maria Krudewig • Meike Hadler • \\ Efstrathios Karagiannis · Ralph Mösges
}

Received: February 22, 2017 / Published online: April 28, 2017

(C) The Author(s) 2017. This article is an open access publication

\section{ABSTRACT}

Introduction: Allergen immunotherapy is the only treatment option for allergic rhinitis with disease-altering potential. It was the objective of this study to assess the effectiveness and tolerability of a 5-grass pollen tablet in a large population of non-selected grass pollen allergic patients, i.e. patients with different clinical profiles in daily clinical practice.

Methods: In a 2-year, prospective, open-label, multicenter, non-controlled, observational study patients were included from 327 centers across Germany. Rhinoconjunctivitis symptoms, symptomatic medication intake and adverse events were recorded.

Results: A total of 1482 patients aged 4-75 years were included. During the 2-year period of 5-grass pollen tablet therapy, mean rhinoconjunctivitis score decreased

Enhanced Content To view enhanced content for this article go to http://www.medengine.com/Redeem/5818 F0601BFC51E4.

K. Shah-Hosseini · E.-M. Krudewig · R. Mösges $(\bowtie)$ Institute of Medical Statistics, Informatics and Epidemiology, Faculty of Medicine, University of Cologne, Cologne, Germany

e-mail: ralph@moesges.de

M. Hadler · E. Karagiannis

Stallergenes GmbH, Kamp-Lintfort, Germany significantly in the overall study population by $65.5 \%(P<0.001)$. The percentage of patients taking symptomatic medication decreased from $83.8 \%$ to $42.7 \%$. Mean 2-year improvements in rhinoconjunctivitis scores and decreases in the percentage of patients taking symptomatic medication were broadly similar in adults, adolescents and children, in patients with polyallergy versus monoallergy, and in patients with/without asthma. Among polyallergic patients, concomitant application of another specific immunotherapy did not impair treatment outcomes. Adverse drug reactions, predominantly affecting the local application area, occurred in $15.4 \%$ of the overall patient population $(n=229)$. No cases of anaphylaxis or epinephrine use were documented.

Conclusion: This study indicates that sublingual immunotherapy with the 5-grass pollen tablet is well tolerated and provides sustained effectiveness over 2 years in patients with different clinical profiles, producing a significant decrease in allergic symptoms and a reduction in the use of symptomatic medication.

Funding: Stallergenes $\mathrm{GmbH}$.

Keywords: Allergic asthma; Allergic rhinoconjunctivitis; Allergy; Grass pollen tablets; Polyallergic; $\quad$ Sublingual immunotherapy (SLIT) 


\section{INTRODUCTION}

The Global Asthma and Allergy European Network study listed prick test confirmed grass sensitization as the most clinically relevant allergic sensitization in Europe [1, 2]. Between $51 \%$ and $81 \%$ of US and European patients with allergic rhinitis (AR) are sensitized to multiple allergens [3]. There is evidence that the development of sensitivity to multiple allergens is a dynamic process in which the number of sensitizations may increase with age [2, 4, 5]. Polysensitization has been associated with increased disease severity [6-8] and, consequently, greater impairment of quality of life. Furthermore, patients with AR are more likely to develop allergic asthma if the condition remains untreated [1]. Therefore, early intervention appears to be important.

Allergen immunotherapy (AIT) is the only treatment option for AR with disease-modifying potential [9]. Provided a recommended treatment period of 3 years [10] has been completed, persistent symptom reduction beyond the treatment period can be expected in most cases [11-13]. Several randomized, double-blind, placebo-controlled (DBPC) studies have shown that sublingual AIT with tablets is well tolerated and effective in the treatment of grass pollen-induced allergic rhinoconjunctivitis (RC) [14-16]. On the basis of a successful clinical development program with randomized DBPC trials, a 5-grass pollen tablet (Oralair ${ }^{\circledR}$; Stallergenes, Antony, France) became one of the first immunotherapy tablets to be approved for clinical use in 2008 (Europe), and it was approved for use in the USA in 2014.

Although they are regarded as the gold standard for clinical evidence, randomized DBPC trials have some important limitations. For example, small sample sizes and restrictive inclusion criteria mean that accurate representation of the real-life patient population is not a certainty, and tightly controlled research conditions may not reflect real-life clinical practice [17]. Observational (non-interventional) studies provide a valuable means of compensating for these limitations [18]. Such studies are unlikely to fundamentally challenge the insights gained from well-designed clinical trials, but they provide a useful means of understanding how the results of conventional trials are manifested in real-life clinical practice. Non-interventional studies are, for example, suitable for investigating under real-life conditions the safety and tolerability of a drug that has been authorized for use. Two previous real-life studies have been performed with the 5 -grass pollen tablet $[19,20]$. These studies, one in children/adolescents and one in adults, were principally concerned with safety/tolerability. The authors of both studies concluded that the 5-grass pollen tablet is "safe and well tolerated".

We performed the first 2-year, real-life, non-interventional study of AIT using the 5-grass pollen tablet. The study was designed to assess the real-life effectiveness and tolerability of the 5 -grass pollen tablet in patients with different clinical profiles and to investigate treatment options for grass pollen allergic patients. Our intention was to study a large sample to provide results that represent the breadth of real-life clinical practice, with an emphasis on different subtypes of patients, e.g., different age groups, asthmatic patients, and polyallergic patients (i.e. patients with clinically relevant symptoms caused by more than one allergen). One-year results from the study showed a significant $49.9 \%$ reduction in rhinoconjunctivitis score for the overall population, with similar responses among polyallergic and monoallergic patients [21]. Here, we present the 2-year follow-up data.

\section{METHODS}

\section{Study Design}

This was a prospective, open-label, uncontrolled, multicenter, non-interventional study performed in Germany between September 2010 and November 2012. The study protocol was approved by the Medical Ethics Committee of the Faculty of Medicine, University of Cologne, in August 2010, OA/2010/002/D. During the 2-year observation phase a total of eight visits (four per year) were planned: inclusion visit 1 (V1)/treatment restart visit (V5) preceding the grass pollen season, two 
intermediate assessments (V2/V3/V6/V7), and a final visit (V4/V8) at the end of the grass pollen season. During each visit investigators filled in a case report form (CRF) for each patient. Study participants were required to give written informed consent according to Germany's Federal Data Protection Act. Demographic data, history of AIT, allergy status, concomitant immunotherapy, comorbidities and start of therapy were documented at V1. Further retrospective documentation included severity and frequency of allergic symptoms (rhinitis, conjunctivitis, asthma) and use of symptomatic medication in the preceding grass pollen season at V1, after the first treatment season at V4 and similarly before (=V4) and after the second treatment season (at V8) for comparability of the results. Also documented were overall health (at V4/V8); investigator- and patientassessed tolerability (V2-V8); adverse events (V2-V8); treatment adherence, evaluated by the investigator (V2-V4, V6-V8); and whether patients would like to continue the treatment.

Symptom severity was measured using rating scales as described by Sieber et al. [22], and this was used to assess the effectiveness of the 5-grass pollen tablet. As primary outcome measure for effectiveness, a RC symptom score (scale 0-6) was obtained by adding together the values for severity of rhinitis (scale 0-3) and for severity of conjunctivitis (scale $0-3$ ). An asthma symptom score (scale $0-7$ ) was created by adding the values for frequency and severity. Patients' use of symptomatic medication was also documented. Tolerability was assessed by both the patient and the investigator as "very good", "good", "moderate" or "poor". For safety evaluation, any occurrence of adverse events [AEs; including serious AEs (SAEs)] was documented and classified according to the Medical Dictionary for Regulatory Activities (MedDRA).

Pollen counts, measured by the German pollen information service, were comparable during the 2010, 2011 and 2012 seasons [23].

\section{Patient Selection}

Resident physicians from across Germany, specialized in allergology $(n=327)$, participated as investigators in this study. Each investigator was asked to include consecutive patients who had been prescribed the 5-grass pollen tablet according to the summary of product characteristics (SmPC) (i.e. grass pollen allergic rhinitis and no contraindications) [24]. Thus, inclusion criteria were adults, adolescents and children (from the age of 5 years) with grass pollen allergy confirmed by clinically relevant symptoms and a positive cutaneous test or a positive titer of specific grass pollen IgE. Exclusion criteria were hypersensitivity to any of the excipients of the 5-grass pollen tablet; treatment with a beta-blocker; severe or unstable asthma [forced expiratory volume in $1 \mathrm{~s}\left(\mathrm{FEV}_{1}\right)<70 \%$ of predicted value]; severe immunodeficiency or auto-immune disease; malignant disease (e.g., cancer); and oral inflammation (e.g., oral lichen planus, oral ulcerations or oral mycosis). Only patients whose treatment plan had already been outlined were enrolled in the study.

Patients were classified as monoallergic or polyallergic according to the case report form question "Does the patient have any other allergies?" (answer, yes or no). Similarly, presence/absence of asthma was based on the question "Does the patient have asthmatic symptoms?".

\section{Study Drug}

Patients were treated with Oralair $^{\circledR}$, a 5-grass pollen tablet containing cocksfoot (Dactylis glomerata), meadow (Poa pratensis), perennial rye (Lolium perenne), sweet vernal (Anthoxantum odoratum) and timothy (Phleum pratense) grasses. Tablets with an index of reactivity (IR) of 100 were administered during a 2-day up-titration phase, and 300 IR tablets were used for the maintenance phase. The dosing regimen and treatment duration were individualized for each patient, based on the SmPC [24] and clinical evaluation of the patient. The tablet is administered sublingually and must be held under the tongue for at least $1 \mathrm{~min}$ until it has completely dissolved. Concomitant immunotherapies and symptomatic anti-allergic medication were permitted in accordance with the SmPC. 


\section{Statistical Methods}

The results were analyzed using data from all patients who participated. Drop-outs meant that the number of patients decreased as the study progressed, and there was no imputation of missing values. Nominal and ordinal data were described by mean, standard deviation, minimum, maximum, median, the number of valid values, and absolute and relative frequency. Intraindividual differences between survey dates were analyzed by the Wilcoxon signed-rank test and the Mann-Whitney $U$ test to ascertain whether statistical significance had been reached. Differences between groups were analyzed by $\chi^{2}$ test or Fisher's exact test (two-tailed).

\section{RESULTS}

A total of 1482 patients (722 male, 752 female), with a mean age of $27.7 \pm 14.9$ years (range 4-75) were included in the study. The median duration of RC prior to 5-grass pollen tablet therapy was 4.7 years (Table 1 ).

Seventy percent $(n=1005)$ of the patients had experienced severe RC ( $\mathrm{RC}$ score $=4-6)$ in the grass pollen season preceding treatment with the 5-grass pollen tablet. Drop-outs occurred in $24.3 \%$ of patients in the first cycle of treatment (V1-V4) and decreased to $20.8 \%$ in the second treatment period (V5-V8) (Fig. 1).

\section{Effectiveness}

In the overall study population, the mean RC score was $4.06 \pm 1.47$ during the season preceding 5-grass pollen tablet treatment and $1.45 \pm 1.19$ during the second season (Table 2).

The delta value, reflecting the improvement from the season preceding treatment with the 5 -grass pollen tablet to the end of the second season, was $\Delta=2.66 \pm 1.68$. This represented a statistically significant improvement of $65.5 \%$ over the course of the study $(P<0.001)$. The sustained effectiveness of treatment in the second season was also confirmed by a decrease in

Table 1 Demographic data and baseline characteristics of the overall study population and subgroups

\begin{tabular}{lllll}
\hline Populations & $\begin{array}{l}\text { Number of patients at } \\
\text { inclusion, } \boldsymbol{n}(\%)\end{array}$ & $\begin{array}{l}\text { Age (years), } \\
\text { mean } \pm \text { SD }\end{array}$ & $\begin{array}{l}\text { RC score at season 0, } \\
\text { mean } \pm \text { SD }\end{array}$ & $\begin{array}{l}\text { Duration of RC (years) at } \\
\text { inclusion, median (range) }\end{array}$ \\
\hline $\begin{array}{l}\text { Overall study } \\
\text { population }\end{array}$ & $1482(100)$ & $27.7 \pm 14.9$ & $4.06 \pm 1.47$ & $4.67(0-58)$ \\
Adults & $1020(69.4)$ & $34.9 \pm 12.1$ & $4.06 \pm 1.49$ & $6.00(0-58)$ \\
$\begin{array}{c}\text { Adolescents } \\
\text { Children }\end{array}$ & $201(13.7)$ & $14.3 \pm 1.6$ & $4.05 \pm 1.54$ & $3.46(0-15)$ \\
$\begin{array}{l}\text { Patients with } \\
\text { asthma }\end{array}$ & $522(38.2)$ & $8.9 \pm 1.8$ & $4.10 \pm 1.38$ & $2.58(0-9)$ \\
$\begin{array}{c}\text { Patients } \\
\text { without }\end{array}$ & $846(61.8)$ & $28.5 \pm 15.4$ & $3.94 \pm 1.72$ & $5.58(0-43)$ \\
$\begin{array}{c}\text { asthma } \\
\begin{array}{c}\text { Monoallergic } \\
\text { patients }\end{array}\end{array}$ & $444(30.5)$ & $27.4 \pm 14.4$ & $4.12 \pm 1.31$ & $4.50(0-58)$ \\
$\begin{array}{l}\text { Polyallergic } \\
\text { patients }\end{array}$ & $1011(69.5)$ & $28.2 \pm 15.0$ & $3.78 \pm 1.60$ & $3.42(0-44)$ \\
\hline
\end{tabular}

$A I T$ allergen immunotherapy, $R C$ score rhinoconjunctivitis symptom score, $S D$ standard deviation, Season 0 season preceding AIT 


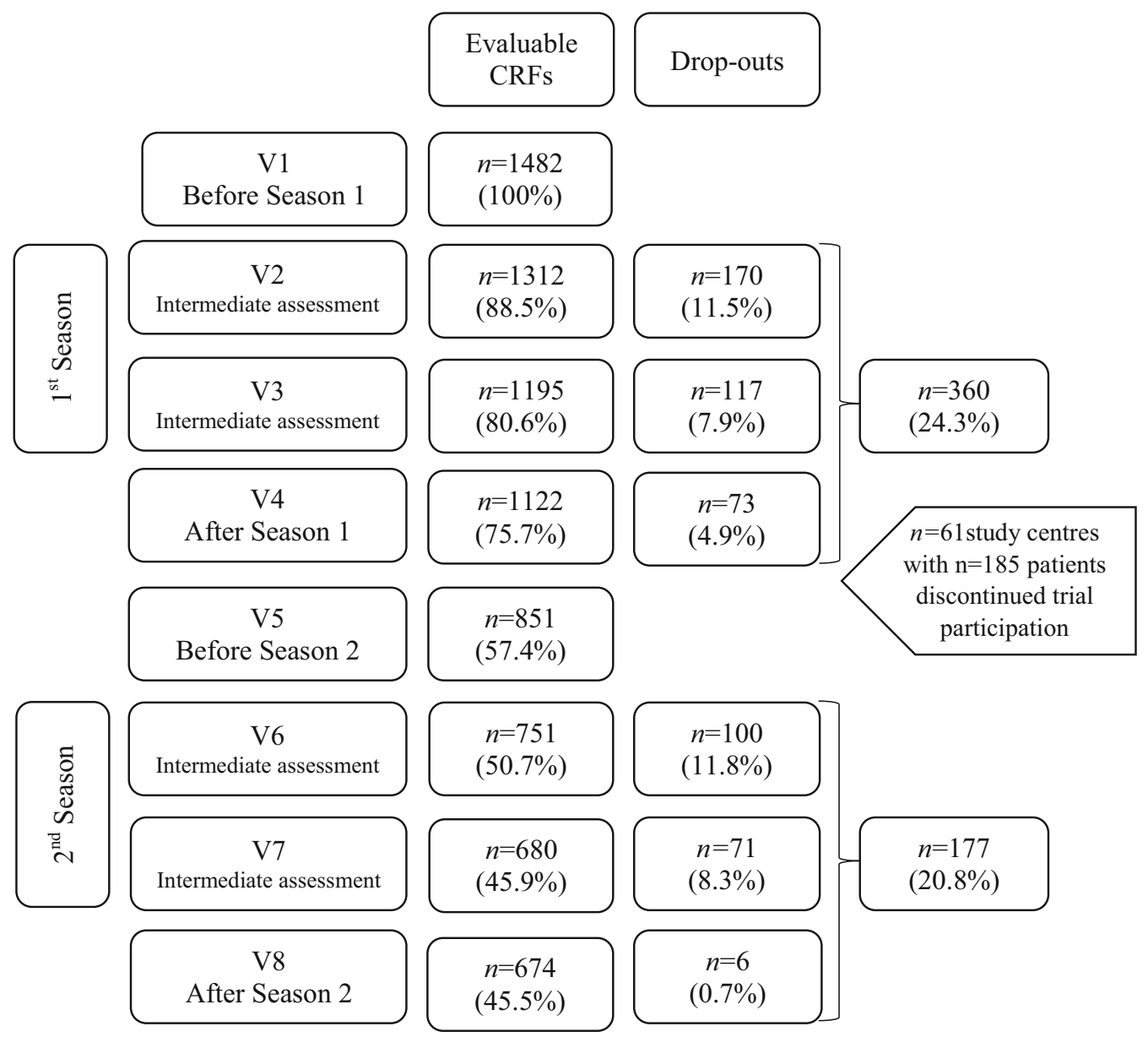

Fig. 1 Flowchart of study population. CRF case report form, Season 0 season preceding AIT, Season 1 1st season with AIT, Season 2 2nd season with AIT, $V$ visit

the percentage of patients taking symptomatic medication, from $83.8 \%$ in the season preceding 5-grass pollen tablet treatment to $42.7 \%$ during the second season $(P<0.001)$. The great majority $(96.9 \%)$ of patients remaining in the study until the end of the second season had "always" or "predominantly" taken the AIT as instructed. At the end of the second year (V8), $90.9 \%$ of the remaining subjects expressed a wish to continue their treatment.

\section{Tolerability and Safety}

A total of 464 patients rated the tolerability of the 5-grass pollen tablet as "very good" at the end of the second season (V8), and 172 rated it as "good". Ratings of "moderate" and "bad" were given by 9 and 6 patients, respectively.
Thus, $97.7 \%$ of the remaining population gave ratings of "good" or "very good".

Overall, 530 AEs were experienced by 237 participants (16.0\%) during the observation phase, of which 509 AEs in 229 patients (15.4\%) were adverse drug reactions (ADRs), i.e. possibly to certainly related to the 5-grass pollen tablet (Table 3).

The majority (93.1\%) of these ADRs occurred during the first study year [21]. The most frequent ADRs were local reactions at the application site, particularly throat irritation, mouth edema and oral paresthesia (Table 3). Most of the ADRs (68.4\%) were mild to moderate, while $21.2 \%$ were classified as severe in intensity. Of the reported ADRs, $78.8 \%$ had already resolved at the time of documentation, 5.9\% were ongoing, and for $15.3 \%$ the outcome was not documented. 


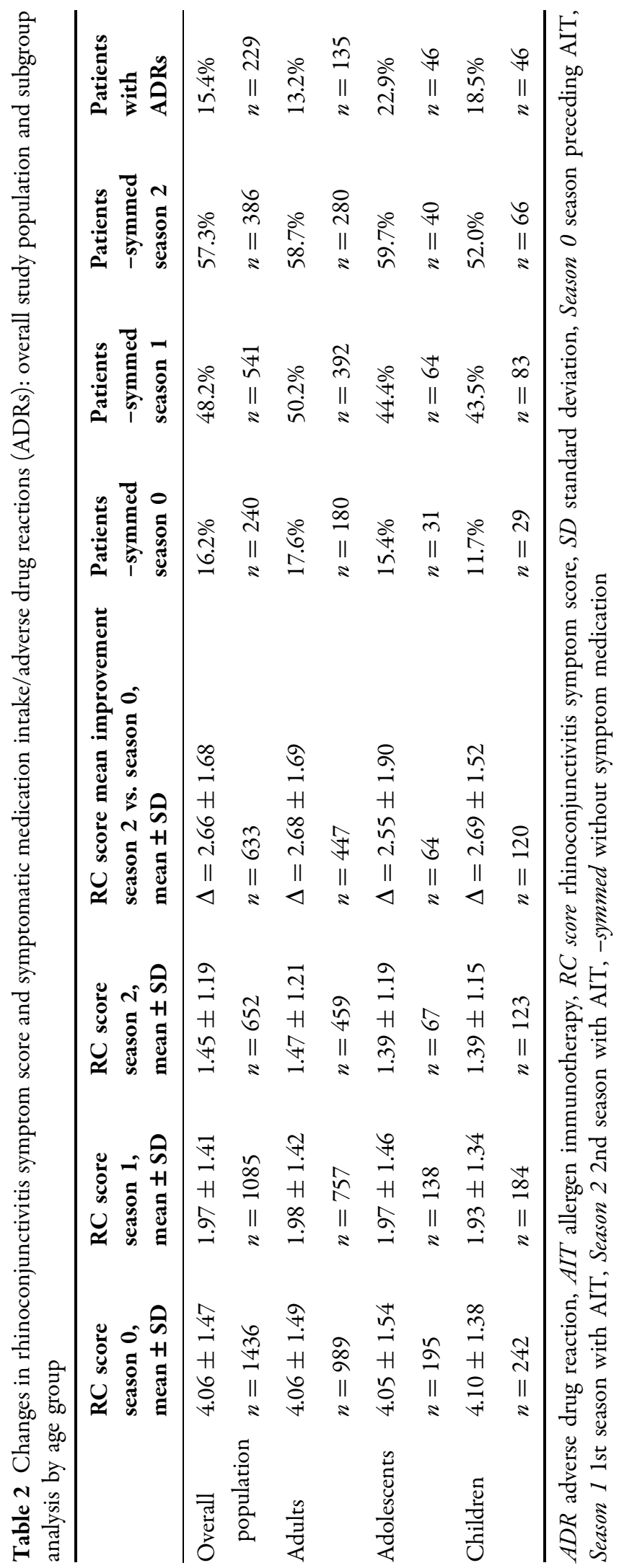


Table 3 AEs/ADRs in the overall study population during the two study years

\begin{tabular}{lll}
\hline & Number of patients, $\boldsymbol{n}$ (\%) & Number of events \\
\hline AEs (total) & $237(16.0)$ & 530 \\
ADRs (total) & $229(15.4)$ & 509 \\
Most common ADRs (by MedDRA PT) & & \\
Gastrointestinal disorders & & \\
Mouth edema & $33(2.2)$ & 33 \\
Oral paresthesia & $25(1.7)$ & 27 \\
Oral pruritus & $20(1.3)$ & 20 \\
Tongue edema & $17(1.1)$ & 18 \\
Nausea & $15(1.0)$ & 16 \\
Respiratory, thoracic and mediastinal disorders & 50 \\
Throat irritation & $44(3.0)$ & 19 \\
Dyspnea & $19(1.3)$ & \\
\hline
\end{tabular}

$A D R$ adverse drug reaction, $A E$ adverse event, MedDRA PT Medical Dictionary for Regulatory Activities Preferred Term

${ }^{a}$ ADRs occurring in at least $1 \%$ of the overall study population

Thirty-nine serious AEs (SAEs) were reported, affecting $0.7 \%$ ( $n=10$ patients) of the overall population. Thirty-three of these, occurring in seven patients $(0.5 \%)$, were possibly to certainly related to the study medication, i.e. serious ADRs (SADRs). None were life-threatening or required the use of epinephrine. The majority of SADRs (30, occurring in six patients) were reported during the first study year, and these have been described previously [21]. Three SADRs occurred in the second study year, all on day 6 in the same patient (a 27-year-old man): pharyngeal edema, throat irritation and sneezing.

\section{Subgroup Analysis: Age Groups}

The majority of study participants were aged $\geq 18$ years $(n=1020)$, with 201 aged 12-17 years and 248 aged $4-11$ years ( 2 patients aged 4 years, i.e. below the minimum age specified in the study inclusion criteria, were included in the youngest age group). Asthma was present in $37.1 \%$ of the adults, $41.0 \%$ of the adolescents and $40.6 \%$ of the children. The percentage of polyallergic patients was $68.4 \%$ among adults, 77.8\% among adolescents and $67.1 \%$ among children. All three age groups entered the study with similar mean RC scores (Table 1). This degree of similarity persisted throughout the study for the second season (Table 2). Accordingly, mean second-season RC score improvements versus the season preceding AIT were also similar in the three age groups (all $P<0.001$; no significant differences in improvement between age groups). $82.4 \%$ of adults needed symptomatic medication during the pollen season preceding treatment with the 5 -grass pollen tablet, compared with $84.6 \%$ of adolescents and $88.3 \%$ of children. During the second season of treatment with the 5-grass pollen tablet, these percentages were significantly lower $(P<0.001$ in all subgroups; no significant differences between age groups) (Table 2). The percentage of patients evaluating tolerability at V8 as "good" to "very good" was high in all three age groups (adults $=97.6 \%$, adolescents $=98.5 \%, \quad$ children $=97.5 \%$ ). Among the adults, 135 individuals (13.2\%) were affected by ADRs, compared with 46 adolescents (22.9\%) and 46 children (18.5\%). There was a significant difference in the incidence of ADRs 
between children and adults $(P=0.046)$ and adolescents and adults $(P=0.004)$, but not between children and adolescents $(P=0.435)$. SADRs were reported in four adult patients $(0.4 \%)$, none of the adolescents $(0 \%)$ and three of the children $(1.2 \%)$.

\section{Subgroup Analysis: Patients with Asthma}

More than a third of the overall study population $(38.2 \% ; n=522$; by age group: adults $37.1 \% ; n=353$; adolescents: $41.0 \% ; n=73$; children: $40.6 \% ; n=93$ ) had asthma in the season preceding 5 -grass pollen tablet treatment, while 846 individuals did not have asthma. A significantly higher percentage of patients with asthma were polyallergic $(74.0 \%)$, compared to patients without asthma $(67.9 \%)$ $(P=0.018)$. The mean RC score during the season preceding 5-grass pollen tablet treatment among patients with asthma was lower compared with individuals without asthma (Table 1). During the second season, these scores were $1.59 \pm 1.32$ and $1.41 \pm 1.09$, respectively (Table 4 ).

These data represent significant improvements in both subgroups $(P<0.001)$, with a larger improvement among patients without asthma $(P=0.019)$ (Table 4$)$. Among patients with asthma, the frequency and severity of asthma symptoms also decreased between the season preceding 5 -grass pollen tablet treatment and the second year: by $67.4 \%$ (from $3.56 \pm 1.58$ in the season preceding treatment to $1.42 \pm 1.48$ during the first season of treatment and $1.08 \pm 1.37$ in the second treatment season; $\Delta=2.40 \pm 1.74, \quad P=0.001 ; \quad$ by age group: adults: $64.3 \%$ (3.55 \pm 1.57 to $1.51 \pm 1.54$ and $1.13 \pm 1.42, \Delta=2.29 \pm 1.75)$; adolescents: $86.0 \% \quad(3.36 \pm 1.61$ to $1.24 \pm 1.33 \quad$ and $0.71 \pm 1.15, \Delta=2.89 \pm 1.41)$; children: $69.1 \%$ $(3.71 \pm 1.61$ to $1.17 \pm 1.32$ and $1.06 \pm 1.28$, $\Delta=2.57 \pm 1.83$ ). During the pollen season preceding treatment with the 5-grass pollen tablet, $90.0 \%$ of individuals with asthma took symptomatic medication for rhinoconjunctivitis symptoms, compared with $80.5 \%$ of those without asthma $(P<0.001)$. A numerical difference in this regard was maintained through the study (Table 4). Therefore, during the second season with 5 -grass pollen tablet treatment, both subgroups exhibited a significant reduction in their use of symptomatic medication $(P<0.001)$, with a significantly larger reduction in patients without asthma $(P<0.001)$. However, patients with asthma had a significantly lower RC score (i.e. they were in better health) at the beginning of the study than patients without asthma $(P=0.02)$. Treatment tolerability was rated as "good" to "very good" at V8 by $97.0 \%$ of individuals with asthma and $98.1 \%$ of those without asthma. ADRs were reported in similar percentages of patients with and without asthma $(P=0.48)$. SADRs affected three patients with asthma $(0.6 \%)$ and two patients without asthma (0.2\%).

\section{Subgroup Analysis: Patients with Polyallergy}

There were more than twice as many polyallergic $(n=1011$; by age group: adults $68.4 \%$; $n=687$; adolescents: $77.8 \% ; n=154$; children: $67.1 \% ; n=163)$ as monoallergic $(n=444$; by age group: adults $31.6 \% ; n=317$; adolescents: $22.2 \%$; $n=44$; children: $32.9 \% ; n=80$ ) participants. Among the polyallergic population, allergy to tree pollen was the most common (70.4\%; $n=712$ ). Asthma was significantly more frequent among polyallergic than monoallergic patients $(40.2 \%$ vs. $33.3 \%$; $P=0.02$ ). Polyallergic patients had a higher mean RC score in the season preceding treatment than monoallergic patients (Table 1). This difference persisted throughout the study (Table 5).

The mean RC score showed significant improvement $(P<0.001)$ in response to the 5 -grass pollen tablet among both polyallergic patients and monoallergic patients. The extent of improvement was not statistically different between these two groups $(P=0.55) .84 .0 \%$ of polyallergic patients needed symptomatic medication during the pollen season preceding treatment with the 5-grass pollen tablet, compared with $82.7 \%$ of monoallergic patients. During the second season of treatment with 


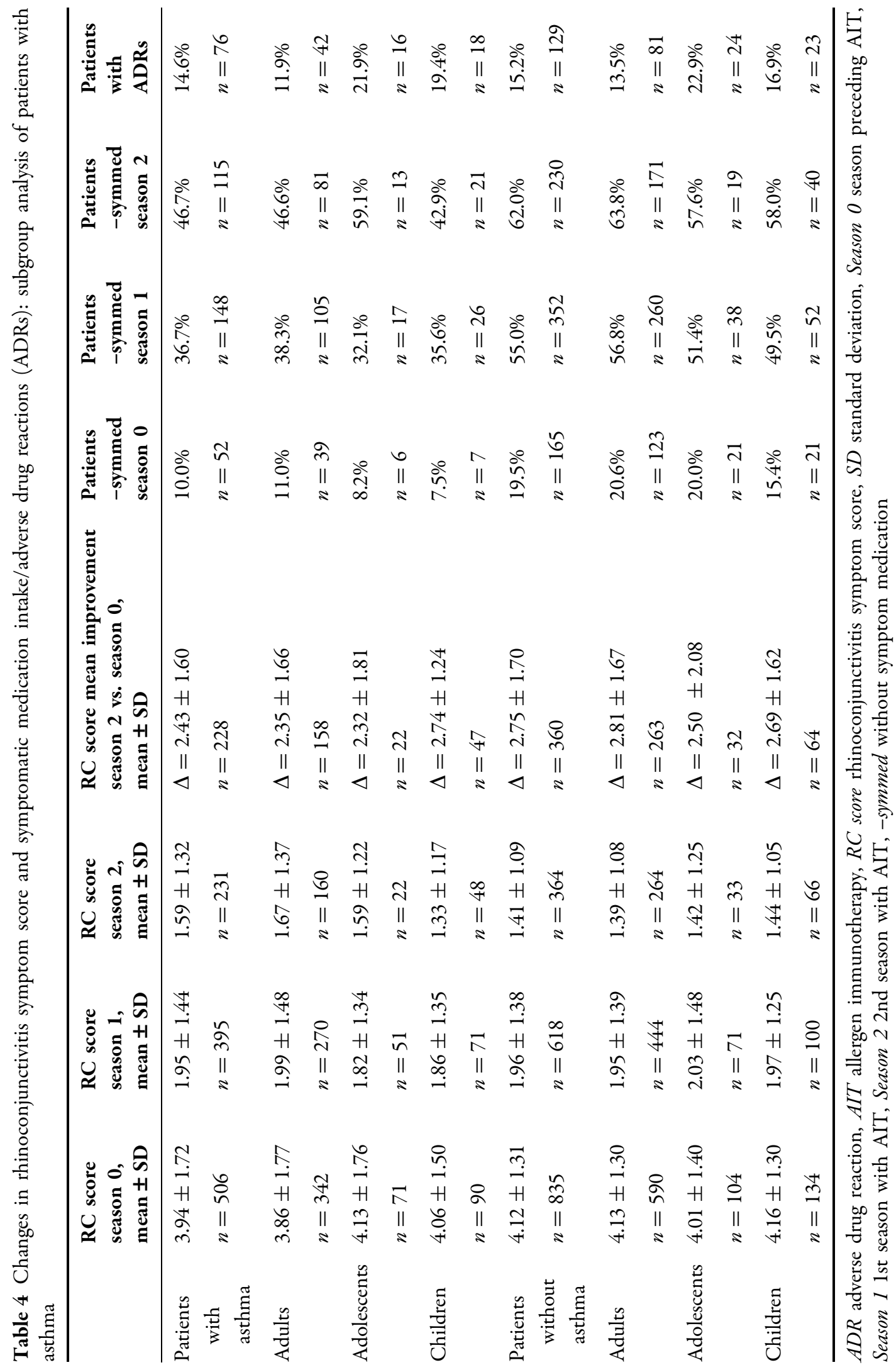




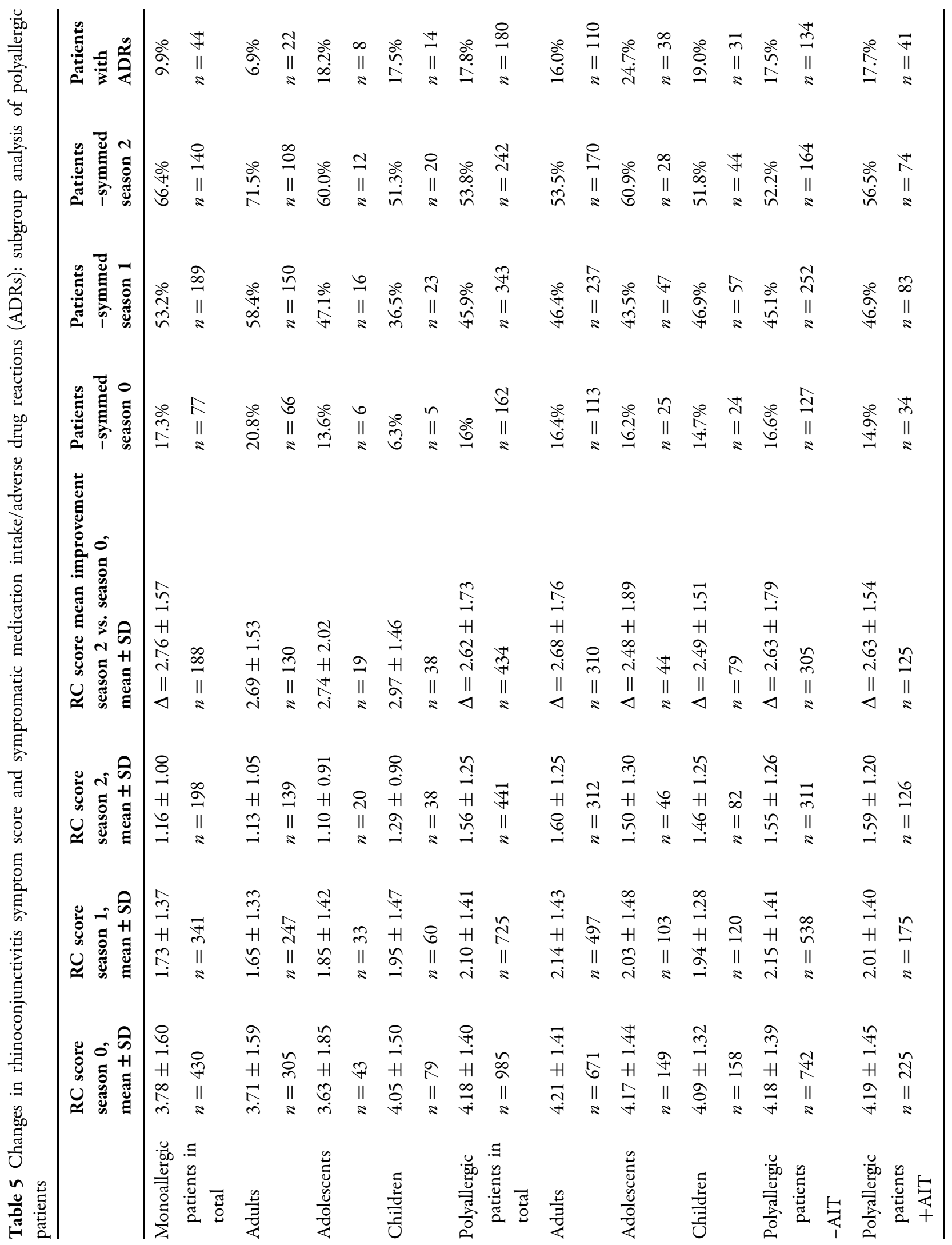




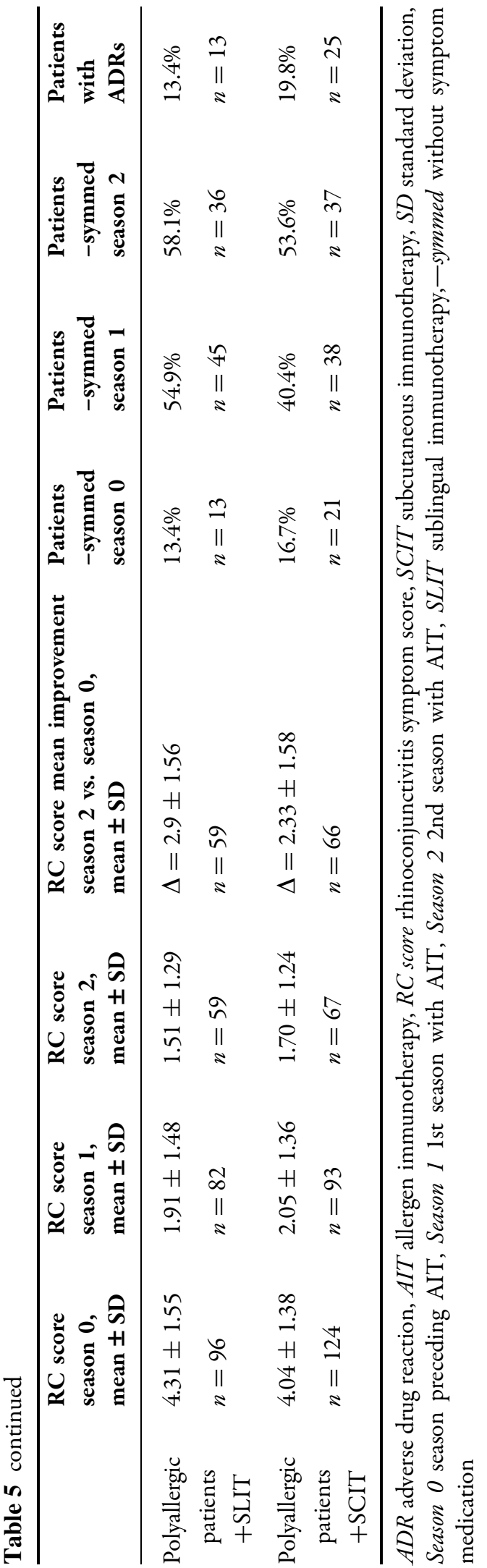

the 5-grass pollen tablet, this percentage decreased significantly $(P<0.001)$ in both groups of patients. The reduction among monoallergic patients was significantly lower than that for polyallergic patients $(P=0.002)$. The patients of both treatment groups evaluated tolerability at V8 as "good" to "very good" in almost $100 \%$ of the cases (monoallergic $=98.5 \%$, polyallergic $=97.3 \%$ ). Of polyallergic patients, $17.8 \%(n=180)$ reported that they had experienced an ADR, compared to $9.9 \% \quad(n=44)$ in the monoallergic group $(P<0.001)$. SADRs affected four polyallergic patients $(0.4 \%)$ and three monoallergic patients $(0.7 \%)$.

\section{Concomitant Immunotherapy}

A total of 228 polyallergic patients (23.0\% of the polyallergic population) received concomitant AIT alongside study medication for a clinically relevant sensitization other than grass pollen. Concomitant AIT was administered subcutaneously in $56.5 \%(n=126)$ of patients and sublingually in $43.5 \%(n=97)$. During the second season of treatment, polyallergic patients without concomitant AIT $(n=764,77.0 \%$ of the polyallergic population) reached a similar mean RC score compared with those with concomitant AIT (Table 5). The delta values for the two populations were identical in both of these subgroups $(P=0.78)$. A greater improvement in RC score was observed among polyallergic patients receiving concomitant SLIT versus concomitant SCIT $(64.5 \%$ vs. $57.9 \% ; P=0.04)$. Polyallergic patients receiving concomitant AIT rated the tolerability of therapy at V8 as "good to very good" in $98.5 \%(n=125)$ of cases. This percentage was similar to that in the polyallergic population without concomitant AIT $(96.7 \%, n=300)$. The percentage of patients reporting ADRs was similar among polyallergic population who were or were not receiving concomitant AIT $[18.0 \%(n=41)$ vs. $17.5 \%$ $(n=134) ; P=0.94]$. None of the polyallergic patients with concomitant AIT experienced any SADR. Twenty-five patients (19.8\%) with concomitant SCIT experienced an ADR, compared with 13 subjects (13.4\%) with concomitant SLIT. 


\section{DISCUSSION}

This 2-year non-interventional study, performed in a real-life setting, showed that treatment with the 5-grass pollen tablet was well tolerated, produced a significant improvement in allergic symptoms (as measured by the RC score) and reduced the need for symptomatic medication in an unselected patient population. These outcomes confirm that the results of clinical trials of the 5-grass pollen tablet are reproducible in clinical practice. For example, our data are consistent with the results of a large $(n=633)$, DBPC trial [16]. The present study is also valuable in contributing to evidence that the effectiveness of treatment with the 5-grass pollen tablet observed is sustained: the effectiveness observed over a single grass pollen season was maintained or improved during a second season of treatment. In a previous pooled analysis of studies documenting 5 years of experience, the daily combined score showed an overall $28.1 \%$ improvement with the 5 -grass pollen tablet versus placebo [25]. Significant benefits versus placebo were also evident in a range of patient subgroups including polysensitized and monosensitized patients; the difference versus placebo was not statistically significant among patients with mild asthma but this was attributable to a small number of patients in this subgroup.

In our study, AIT was effective and well tolerated in a variety of patient subgroups. This was the case in different age groups, reflecting the findings of previous studies performed in adults [15] and children/adolescents [14, 26]. There were differences between age groups in the incidence of ADRs in our study, the lowest rate being in adults. One possible contributing factor to the higher rates in children and adolescents might be the closer monitoring given by parents and caregivers to this population. In a position paper by Church et al., it is reported that side effects, such as somnolence, of standard allergy medication vary from $40 \%$ to $80 \%$ [33], which is much higher than the overall incidence reported in our study.

Improvement in RC score and favorable tolerability has been shown previously in patients with or without asthma [27], and the potential effectiveness of SLIT in treating the symptoms of asthma has also been demonstrated $[28,29]$. Accordingly, in our study, treatment with the 5 -grass pollen tablet was associated with reduced frequency and severity of asthma symptoms.

Over two-thirds of patients in our study (69\%) were allergic to allergens other than grass pollen, most commonly tree pollen. This result is similar to previous data based on skin prick tests and IgE assays, showing that $51 \%-81 \%$ of allergic rhinitis patients are sensitized to multiple allergens [3]. However, in our study population, the proportion of polyallergic patients may have been increased by the investigators' specialization in allergology. As polyallergy leads to increased impairment of quality of life, a polyallergic patient may be more likely to consult allergists for specific treatment [30]. Our study results are consistent with previous data in showing a higher disease burden in polyallergic patients, based on the higher RC score at study entry in this patient subgroup.

On the one hand, there is no published evidence that the study AIT offers a cross-protection to tree pollen, as recent data by Gadermaier et al. demonstrated that a small number of amino acid differences among allergen epitopes can reduce the binding affinity by AIT-induced IgG4 antibodies and thus limit potential cross-protection [31]. On the other hand, it has been suggested that polyallergy may reduce the efficacy of AIT $[9,27]$. The results obtained here show clinically and statistically significant benefits of treatment with the 5-grass pollen tablet $(P<0.001)$ among both monoallergic and polyallergic patients, with no significant difference between these groups. Reductions in the severity of allergic symptoms were accompanied by significant decreases in the use of symptomatic medication. Furthermore, according to patient assessment, the drug was well tolerated among patients with and without polyallergy. There were significantly more ADRs in polyallergic than in monoallergic patients. In this study, the tolerability of the 5-grass pollen tablet appeared similar in patients with or without concomitant AIT. Since polypharmacy 
increases the risk of ADRs, it is considered feasible to combine preparations with the most advantageous safety profiles. Findings by Agostinis et al. also indicate that the sublingual administration of multiple allergens in children did not increase the occurrence of ADRs compared to monotherapy [32]. SLIT is generally considered more convenient than SCIT as it does not require regular doctor's appointments and can easily be administered at home. Furthermore, potentially life-threatening ADRs such as anaphylaxis are extremely rare with SLIT in comparison with SCIT [9].

Drop-out is an important outcome as it may indicate drug tolerability and effectiveness. This trial was initially scheduled as a 1-year observation period. With an excellent adherence rate of more than three-quarters of the patients continuing treatment over the first season, the decision was taken to extend the trial for another year. This, however, resulted in an alleged rise in drop-outs between $\mathrm{V} 4$ and V5 which was not due to an actual drop-out of patients but to an expiration of contract with certain study centers that did not participate and therefore did not contribute patients to the trial during the second year. Thus, no overall drop-out rate for the 2-year period can be generated from our results. But even a drop-out rate of $>50 \%$ in the 2-year study course would be concordant with medication persistence data for SLIT [34]. Reasons for treatment discontinuation after year 2 were mainly a non-response to treatment and lack of tolerability [35]. Those patients who were classified as non-responders entered the trial with a lower RC score in the previous season, suggesting that patients with a moderate-to-severe symptom load benefit more from treatment than other patients. Based on an improvement of two or more points in the RC score, $78.8 \%$ of the patients can be considered as responders.

The uncontrolled, real-life setting of a non-interventional study combined with a large sample size ensure that the results are representative of clinical practice [22]. It is also more likely that rare ADRs and drug interactions are detected which is a valuable contribution to pharmacovigilance. As is usual for this type of study, patients were treated differently according to their individual needs. The limitations of this observational study include the lack of robustness of a DBPC study. Patients were not requested to keep a daily record of their symptoms in the form of symptom diary cards. Instead, data regarding symptoms were taken from the standardized CRFs, which were filled in at different times during the treatment course. Thorough completion of the CRFs as well as the evaluation of the AEs were dependent on the investigators, introducing the possibility of bias. Treatment effectiveness was measured by comparing symptoms observed during treatment with retrospective assessment of the grass pollen season preceding treatment with the 5-grass pollen tablet. Differences between the seasons in pollen levels might have affected the study findings, although for grass pollen the differences were relatively small (7\% lower in 2011 vs. 2010; 11\% higher in 2012 vs. 2011) [23]. Despite the limitations, the methodological approach followed in this study has been supported in principle [36, 37]. It has been suggested that immunotherapy trials are prone to a considerable placebo response with up to $50 \%$. However, in most field studies, the "placebo" group has free access to comprehensive rescue medication. Nolte et al. demonstrated that there is no such thing as a placebo effect in patients who have been challenged in an environmental exposure chamber without the concomitant use of symptomatic medication [38].

\section{CONCLUSIONS}

This non-interventional, observational study shows that SLIT with the 5-grass pollen tablet was effective and well tolerated over 2 years in patients with grass pollen allergy. Significant improvements in allergic symptoms and reductions in the use of symptomatic medication were observed in patients with different clinical profiles (e.g., mono- and polyallergic patients, different age groups, patients with or without asthma). These data confirm that clinical trial results obtained with the 5-grass pollen tablet are reproducible in clinical practice. 


\section{ACKNOWLEDGEMENTS}

Sponsorship for this study and article processing charges and Open Access fees were funded by Stallergenes $\mathrm{GmbH}$, Kamp-Lintfort, Germany. All named authors meet the International Committee of Medical Journal Editors (ICMJE) criteria for authorship for this manuscript. They had full access to all of the data in this study and take responsibility for the integrity of the data and accuracy of the data analysis, and therefore of the work as a whole. They have all given final approval to the version to be published. Medical writing/language editing support was provided by Marie-Josefine Joisten (IMSIE, Cologne, Germany) and Ken Sutor (Newmed Publishing Services, Chester, UK). The authors would like to thank all investigators who provided data on treatment of their patients for the study.

Disclosures. Kija Shah-Hosseini and EvaMaria Krudewig have nothing to disclose. Meike Hadler reports personal fees from Stallergenes $\mathrm{GmbH}$. Efstrathios Karagiannis reports personal fees from Stallergenes GmbH. Ralph Mösges reports personal fees from ALK, grants from ASIT biotech, personal fees from Allergopharma, personal fees from Allergy Therapeutics, grants and personal fees from Bencard, grants from Leti, grants, personal fees and non-financial support from Lofarma, non-financial support from Roxall, grants and personal fees from Stallergenes, grants from Optima, personal fees from Friulchem, personal fees from Hexal, personal fees from Servier, personal fees from Klosterfrau, non-financial support from Atmos, personal fees from Bayer, non-financial support from Bionorica, personal fees from FAES, personal fees from GSK, personal fees from MSD, personal fees from Johnson\&Johnson, personal fees from Meda, personal fees and non-financial support from Novartis, non-financial support from Otonomy, personal fees from Stada, personal fees from UCB, non-financial support from Ferrero, grants from BitopAG, grants from Hulka, personal fees from Nuvo, grants from Ursapharm, outside the submitted work.
Compliance with Ethics Guidelines. The study protocol was approved by the Medical Ethics Committee of the Faculty of Medicine, University of Cologne in August 2010, OA/ 2010/002/D.

Data Availability. The datasets analyzed during and/or after this study are available from the corresponding author on reasonable request.

Open Access. This article is distributed under the terms of the Creative Commons Attribution-NonCommercial 4.0 International License (http://creativecommons.org/licenses/ by-nc/4.0/), which permits any noncommercial use, distribution, and reproduction in any medium, provided you give appropriate credit to the original author(s) and the source, provide a link to the Creative Commons license, and indicate if changes were made.

\section{REFERENCES}

1. Burbach GJ, Heinzerling LM, Edenharter G, Bachert C, Bindslev-Jensen C, Bonini S, et al. GA(2)LEN skin test study II: clinical relevance of inhalant allergen sensitizations in Europe. Allergy. 2009;64(10):1507-15. doi:10.1111/j.1398-9995. 2009.02089.x.

2. Schmitz R, Ellert U, Kalcklosch M, Dahm S, Thamm M. Patterns of sensitization to inhalant and food allergens-findings from the German Health Interview and Examination Survey for Children and Adolescents. Int Arch Allergy Immunol. 2013;162(3):263-70. doi:10.1159/000353344.

3. Ciprandi G, Cirillo I, Vizzaccaro A, Tosca M, Passalacqua G, Pallestrini E, et al. Seasonal and perennial allergic rhinitis: is this classification adherent to real life? Allergy. 2005;60(7):882-7. doi:10.1111/ j.1398-9995.2005.00602.x.

4. Fasce L, Tosca MA, Olcese R, Milanese M, Erba D, Ciprandi G. The natural history of allergy: the development of new sensitizations in asthmatic children. Immunol Lett. 2004;93(1):45-50. doi:10. 1016/j.imlet.2004.01.016.

5. Matricardi PM, Bockelbrink A, Keil T, Gruber C, Niggemann B, Hamelmann E, et al. Dynamic evolution of serum immunoglobulin $\mathrm{E}$ to airborne allergens throughout childhood: results from the 
Multi-Centre Allergy Study birth cohort. Clin Exp Allergy. 2009;39(10):1551-7. doi:10.1111/j.13652222.2009.03348.x.

6. Ciprandi G, Incorvaia C, Puccinelli P, Soffia S, Scurati $S$, Frati F. Polysensitization as a challenge for the allergist: the suggestions provided by the polysensitization impact on allergen immunotherapy studies. Exp Opin Biol Ther. 2011;11(6):715-22. doi:10.1517/14712598.2011.576246.

7. Kim KW, Kim EA, Kwon BC, Kim ES, Song TW, Sohn $\mathrm{MH}$, et al. Comparison of allergic indices in monosensitized and polysensitized patients with childhood asthma. J Korean Med Sci. 2006;21(6):1012-6.

8. Mosges R, Klimek L. Today's allergic rhinitis patients are different: new factors that may play a role. Allergy. 2007;62(9):969-75. doi:10.1111/j. 1398-9995.2007.01440.x.

9. Bousquet J, Khaltaev N, Cruz AA, Denburg J, Fokkens WJ, Togias A, et al. Allergic Rhinitis and its Impact on Asthma (ARIA) 2008 update (in collaboration with the World Health Organization, GA(2) LEN and AllerGen). Allergy. 2008;63(Suppl 86):8-160. doi:10.1111/j.1398-9995.2007.01620.x.

10. Bousquet J, Lockey R, Malling HJ. Allergen immunotherapy: therapeutic vaccines for allergic diseases A WHO position paper. J Allergy Clin Immunol. 1998;102:558-62.

11. Durham SR, Walker SM, Varga EM, Jacobson MR, O'Brien F, Noble W, et al. Long-term clinical efficacy of grass-pollen immunotherapy. New Eng J Med. 1999;341(7):468-75. doi:10.1056/ NEJM199908123410702.

12. Didier A, Malling HJ, Worm M, Horak F, Sussman GL. Prolonged efficacy of the 300IR 5-grass pollen tablet up to 2 years after treatment cessation, as measured by a recommended daily combined score. Clin Trans Allergy. 2015;5:12. doi:10.1186/s13601015-0057-8.

13. Durham SR, Emminger W, Kapp A, de Monchy JG, Rak S, Scadding GK, et al. SQ-standardized sublingual grass immunotherapy: confirmation of disease modification 2 years after 3 years of treatment in a randomized trial. J Aller Clin Immunol. 2012;129(3):717. doi:10.1016/j.jaci.2011.12.973.

14. Wahn U, Tabar A, Kuna P, Halken S, Montagut A, de Beaumont $\mathrm{O}$, et al. Efficacy and safety of 5-grass-pollen sublingual immunotherapy tablets in pediatric allergic rhinoconjunctivitis. J Allergy Clin Immunol. 2009;123(1):160. doi:10.1016/j.jaci.2008.10.009.

15. Didier A, Malling HJ, Worm M, Horak F, Jager S, Montagut A, et al. Optimal dose, efficacy, and safety of once-daily sublingual immunotherapy with a 5 -grass pollen tablet for seasonal allergic rhinitis. J Allergy Clin Immunol. 2007;120(6):1338-45. doi:10.1016/j.jaci.2007.07.046.

16. Didier A, Worm M, Horak F, Sussman G, de Beaumont O, Le Gall M, et al. Sustained 3-year efficacy of pre- and coseasonal 5-grass-pollen sublingual immunotherapy tablets in patients with grass pollen-induced rhinoconjunctivitis. J Allergy Clin Immunol. 2011;128(3):559-66. doi:10.1016/j.jaci. 2011.06.022.

17. Akobeng AK. Assessing the validity of clinical trials. J Pediatr Gastroenterol Nutr. 2008;47(3):277-82. doi:10.1097/MPG.0b013e31816c749f.

18. Sieber J, Koberlein J, Mosges R. Sublingual immunotherapy in daily medical practice: effectiveness of different treatment schedules - IPD meta-analysis. Curr Med Res Opin. 2010;26(4):925-32. 03007991003659483 .

19. Eberle P, Brueck H, Gall R, Hadler M, Sieber J, Karagiannis E. An observational, real-life safety study of a 5-grass pollen sublingual tablet in children and adolescents. Pediatr Allergy Immunol. 2014;25(8):760-6. doi:10.1111/pai.12298.

20. Pfaar O, Richter HG, Klimek L, Sieber J, Hadler M, Karagiannis E. Sublingual immunotherapy with a five-grass pollen tablet in adult patients with allergic rhinitis: an open, prospective, noninterventional multicenter study. BioMed Res Int. 2015;2015:584291. doi:10.1155/2015/584291.

21. Shah-Hosseini K, Mioc K, Hadler M, Karagiannis E, Mosges R. Optimum treatment strategies for polyallergic patients-analysis of a large observational trial. Curr Med Res Opin. 2015;31(12):2249-59. doi:10.1185/03007995.2015.1094653.

22. Sieber J, Shah-Hosseini K, Mosges R. Specific immunotherapy for allergic rhinitis to grass and tree pollens in daily medical practice-symptom load with sublingual immunotherapy compared to subcutaneous immunotherapy. Ann Med. 2011;43(6): 418-24. doi:10.3109/07853890.2011.595426.

23. German Pollen Foundation. Literature and lectures. German Pollen Foundation 2016. http://www. pollenstiftung.de/literaturvortraege/studienanaly sen/. Accessed Apr 2016.

24. Stallergenes. Summary of product characteristics: Oralair 2013. http://www.hpra.ie/img/uploaded/ swedocuments/LicenseSPC_PA1580-001-002_2705 2014165056.pdf. Accessed Apr 2016.

25. Didier A, Wahn U, Horak F, Cox LS. Five-grass-pollen sublingual immunotherapy tablet 
for the treatment of grass-pollen-induced allergic rhinoconjunctivitis: 5 years of experience. Exp Rev Clin Immunol. 2014;10(10):1309-24. doi:10.1586/ 1744666x.2014.957677.

26. Halken S, Agertoft L, Seidenberg J, Bauer CP, Payot F, Martin-Munoz MF, et al. Five-grass pollen 300IR SLIT tablets: efficacy and safety in children and adolescents. Pediatr Allergy Immunol. 2010;21(6):970-6. doi:10.1111/j.1399-3038.2010. 01050.x.

27. Malling HJ, Montagut A, Melac M, Patriarca G, Panzner P, Seberova E, et al. Efficacy and safety of 5 -grass pollen sublingual immunotherapy tablets in patients with different clinical profiles of allergic rhinoconjunctivitis. Clin Exp Allergy. 2009;39(3):387-93. doi:10.1111/j.1365-2222.2008. 03152.x.

28. Penagos M, Passalacqua G, Compalati E, Baena-Cagnani CE, Orozco S, Pedroza A, et al. Metaanalysis of the efficacy of sublingual immunotherapy in the treatment of allergic asthma in pediatric patients, 3 to 18 years of age. Chest. 2008;133(3):599-609. doi:10.1378/chest.06-1425.

29. Canonica GW, Cox L, Pawankar R, Baena-Cagnani CE, Blaiss M, Bonini $S$, et al. Sublingual immunotherapy: World Allergy Organization position paper 2013 update. World Allergy Org J. 2014;7(1):6. doi:10.1186/1939-4551-7-6.

30. Calderon MA, Cox L, Casale TB, Moingeon P, Demoly P. Multiple-allergen and single-allergen immunotherapy strategies in polysensitized patients: looking at the published evidence. J Allergy Clin Immunol. 2012;129(4):929-34. doi:10. 1016/j.jaci.2011.11.019.

31. Gadermaier E, James LK, Shamji MH, Blatt K, Fauland $\mathrm{K}$, Zieglmayer $\mathrm{P}$, et al. Epitope specificity determines cross-protection of a SIT-induced IgG4 antibody. Allergy. 2016;71(1):36-46. doi:10.1111/ all.12710.
32. Agostinis F, Foglia C, Landi M, Cottini M, Lombardi $\mathrm{C}$, Canonica GW, et al. The safety of sublingual immunotherapy with one or multiple pollen allergens in children. Allergy. 2008;63(12):1637-9. doi:10.1111/j.1398-9995.2008.01742.x.

33. Church MK, Maurer M, Simons FE, Bindslev-Jensen $C$, van Cauwenberge P, Bousquet J, et al. Risk of first-generation $\mathrm{H}(1)$-antihistamines: a GA(2)LEN position paper. Allergy. 2010;65(4):459-66. doi:10. 1111/j.1398-9995.2009.02325.x.

34. Sieber J, De Geest S, Shah-Hosseini K, Mosges R. Medication persistence with long-term, specific grass pollen immunotherapy measured by prescription renewal rates. Curr Med Res Opin. 2011;27(4):855-61. doi:10.1185/03007995.2011. 559538 .

35. Krudewig E-M, Shah-Hosseini K, Hadler M, Karagiannis E. Einflussfaktoren auf die Therapieadhärenz in der Routinebehandlung mit einer 5-Gräser-Tablette. Allergo J. 2015;24(6):73.

36. Koberlein J, Mosges R. Oralair ${ }^{\circledR}$ : a causal treatment for grass pollen-induced allergic rhinoconjunctivitis. Immunotherapy. 2013;5(1):13-21. doi:10.2217/ imt.12.147.

37. von Elm E, Altman DG, Egger M, Pocock SJ, Gotzsche PC, Vandenbroucke JP, et al. The Strengthening the Reporting of Observational Studies in Epidemiology [STROBE] statement: guidelines for reporting observational studies. Gaceta sanitaria/SESPAS. 2008;22(2):144-50.

38. Nolte H, Maloney J, Nelson HS, Bernstein DI, Lu S, Li Z, et al. Onset and dose-related efficacy of house dust mite sublingual immunotherapy tablets in an environmental exposure chamber. J Allergy Clin Immunol. 2015;135(6):1494. doi:10.1016/j.jaci. 2014.12.1911. 